\title{
Public health nutrition in the UK
}

Dimitrios A Koutoukidis

Susan A Jebb

Dimitrios A Koutoukidis PhD AFHEA is a Researcher on Diet, Obesity, and Lifestyle at the Nuffield Department of Primary Care Health Sciences, University of Oxford, UK. Competing interests: none declared.

Susan A Jebb PhD OBE FMedSci is Professor of Diet and Population Health at the Nuffield Department of Primary Care Health Sciences, University of Oxford, UK. Competing interests: none declared.

\begin{abstract}
A poor diet is the leading cause of premature morbidity and mortality in England. Nutritional surveillance shows that, on average, people eat too little fruit and vegetables, fibre and oily fish, and too many foods and drinks high in calories, sugar and saturated fat. Although micronutrient deficiencies are rare at the population level, some subgroups may require nutritional supplements. Public health policy seeks to intervene to close the gap between dietary intake and dietary recommendations for good health. Population-level policies include actions to enhance nutritional knowledge, set nutrition standards for food provision and introduce fiscal interventions such as taxation. They can also encourage the food industry to reformulate food and drink products, change the availability or positioning of products, thus changing the default choices, and change the way products are marketed, with a mix of both voluntary and mandatory approaches. Health professionals can play a pivotal role in motivating dietary change at an individual level, particularly for individuals with increased risk, and have an advocacy role in supporting policies to improve population health.
\end{abstract}

\section{Keywords}

Dietary recommendations; Dietary Reference Values; micronutrients; National Diet and Nutrition Survey; nutrition policy; Reference Nutrient Intake

\section{Key points}

- There is a large gap between what people currently report eating and dietary recommendations for good health

- A portfolio of different interventions can be deployed to encourage a healthier diet

- Healthcare professionals have opportunities to encourage individuals to make dietary changes that will improve their health, and can act as advocates for effective public health nutrition policies to create a healthier food environment for everyone 


\section{Introduction}

Poor diet is the leading cause of morbidity and premature mortality in England, and indirectly contributes to the risk of obesity, hypertension, insulin resistance and dyslipidaemia. ${ }^{1}$ Improving diet at the population level is crucial to health improvement. In addition, because some aspects of a poor diet are socially patterned, dietary recommendations and targeted public health policies could help to reduce inequalities in health outcomes.

\section{Developing dietary recommendations}

The Scientific Advisory Committee on Nutrition (SACN) is the independent committee that has a rolling programme of work to review evidence and advise government on dietary requirements for the whole population as well as specific vulnerable groups (e.g. infants). It also advises on nutritional issues that affect public health (e.g. in terms of cardiovascular disease or osteoporosis). Nutritional needs for an individual vary because of factors such as sex, age, body size, physical activity and health status.

Recommendations are expressed as Dietary Reference Values (DRVs); these describe the requirements of the population, assuming that nutritional needs are normally distributed (Figure 1): ${ }^{2}$ -Estimated Average Requirements (EARs) - an estimate of the average need for energy or a nutrient. Therefore, half of individuals need less and half need more than the EAR

-Reference Nutrient Intakes (RNIs) - the amount of a nutrient that is sufficient to cover the needs of $97.5 \%$ of the population, for example for use in menu planning

-Low Reference Nutrient intakes (LRNIs) - the amount of a nutrient that is sufficient to cover the needs of $2.5 \%$ of the population. Concern about a possible nutrient deficiency is indicated if $>2.5 \%$ of the population report an intake below the LRNI

-Safe Intake - if the previous three DRVs cannot be established, the amount judged to meet the needs of almost everyone, without having undesirable effects.

Children and some subgroups, such as women who are pregnant or breastfeeding, may have different dietary requirements for some nutrients, and specific recommendations may be issued for these groups.

\section{What do people eat?}

Knowledge of the population's current dietary intake underpins public health nutrition policy. The UK is fortunate to have a long-standing programme of nutrition surveillance with data on food purchases collected at a household level in the Family Food module of the Living Costs and Food Survey, and at an individual level in the National Diet and Nutrition Survey (NDNS). The NDNS surveys about 2300 people annually to provide a representative sample, and measures food and nutrient intake, and nutritional status. Over the last two decades, there has been a gradual change in food choices towards a healthier diet, notably modest increases in fruit and vegetables, but the rate of change is very slow.

Table 1 shows the average intakes of key food groups and macronutrients of UK adults in the period $2014 / 15$ to $2015 / 16$, as well as how these compare with UK dietary recommendations. ${ }^{3}$ People are eating less than the recommended amount of fruit and vegetables, oily fish (e.g. sardines, salmon) and too many sugar-sweetened beverages. Average intakes of red and processed meat across the population are close to the maximum, meaning that most regular meat-eaters are likely to exceed this recommendation.

It is important to note that the reported average energy intake from these surveys is apparently below the recommended intake, yet the national prevalence of obesity is increasing. This discrepancy is caused by an under-reporting of dietary intake. The extent of energy misreporting can be assessed by comparisons with objective measures of energy expenditure (with adjustment for weight change), and is estimated to account for up to a third of energy intake. We can only speculate on the foods and nutrients that are under-reported. Caution is therefore needed in interpreting food intake records, which will, for the most part, underestimate the consumption of nutrients of concern, as well as underestimating the intake of vitamins and minerals.

Recommended energy requirements are based on the needs of people of a healthy weight with typical levels of physical activity. Dietary recommendations for macronutrients are expressed in terms of their contribution to energy intake. In the UK, the average intake of total fat and trans fatty 
acids is within the recommended limits, whereas that of saturated fat, mostly from animal sources including butter, cheese and meat, is higher than recommended. Total carbohydrate intake is slightly lower than recommended, but the proportion of free sugars (e.g. sugary drinks, confectionery, desserts) is greatly in excess of dietary recommendations. Intake of dietary fibre, predominately from cereals and grains, is significantly below the lower recommended limit.

The assessment of the adequacy of micronutrient intake (vitamins, minerals) is based on both reported intake and measures of nutritional status. At a population level, there is little evidence of deficiencies; however, some subgroups have increased needs, for example for folate during the first trimester of pregnancy to reduce the risk of neural tube defects, or for iron in women with heavy menstrual losses. In these cases, a specific nutrient supplement can be recommended (Table 2). Notably, everyone in the UK is recommended to take a vitamin D supplement in autumn and winter, and people who get little sunlight exposure should consider a supplement all year round.

Some people should avoid specific nutritional supplements. For example, vitamin A taken in high doses can be teratogenic and should be avoided by pregnant women. Similarly, research studies testing the potential benefits of $\beta$-carotene supplements for people with lung cancer have shown adverse effects on disease progression. In general, any supplements in excess of the RNI should be avoided unless a specific need has been identified.

\section{Public health nutrition policy}

Public health policy seeks to narrow the gap between current dietary intake, as measured by surveillance programmes, and dietary recommendations for good health. One of the challenges for public health policy is to judge the appropriate level of government intervention in the market and in personal decision-making about food (Figure 2). This partly depends on the prevailing political philosophy and partly on the public's acceptability of intervention.

\section{Raising awareness}

Government and the public mostly have a strong preference for interventions based on information and education. This includes initiatives such as the Change4Life social marketing campaign. These are important to raise awareness of the issue and boost knowledge about a healthy diet, but evidence suggests that these have only a modest impact on behaviour. Educational resources can act as an opener for health professionals to initiate conversations with patients about diet, and signpost patients to other more active interventions, such as weight-management programmes. Other initiatives, such as nutritional labelling of food, can also raise awareness and has been shown to have a small but significant impact on food choices, providing information to allow consumers to enact positive dietary choices. ${ }^{4}$

\section{Changing the content of foods and drinks}

Interventions in the food system that have shown significant benefits include changes to food products to reduce nutrients of concern. The UK government has led a programme to encourage reductions in the salt content of foods, which has led to a decrease in salt intake of $>15 \%$ in a decade. More recently, the food industry has been encouraged to reduce sugar and total energy (calories) in everyday food items. This may include reformulating products, for example reducing the sugar in breakfast cereals or yoghurts, or replacing the sugar in drinks with high-intensity sweeteners. In some categories of foods, there have been noticeable reductions in portion size, for example in single-serving bars of confectionery, although the net effect is unclear if such changes are accompanied by the introduction of other larger sized portions, such as sharing bags.

In some cases, specific micronutrients are added to food to restore those lost in processing, or to fortify food to enhance the nutrient content. This commonly occurs at the manufacturer's discretion (e.g. for breakfast cereals). It is often designed to allow a product to claim to be a 'good source of $X$ ' or better meet the needs of specific population groups (e.g. fortifying vegan products with vitamin $B_{12}$, which is usually available only in animal-based products).

Fortification is occasionally encouraged or even mandated by government to meet a specific nutritional need. White flour in the UK has by law been fortified with calcium, iron and vitamins $B_{1}$ and $B_{3}$ since the time of food rationing in the 1940 s, to reduce the risk of deficiencies. The SACN has recommended that government consider fortifying flour with folic acid, which already occurs in many countries, as a way to increase intake particularly for women in the early stages of pregnancy 
because the uptake of folic acid supplements is low; this has, however, met with some public opposition. Consideration is also being given to fortifying foods, possibly milk, with vitamin $D$, given evidence of the widespread occurrence of low vitamin D status across the UK population especially during the winter months. Currently, however, the policy remains of recommending supplements to those groups at highest risk (Table 2).

\section{Changing the default option}

Interventions in 'choice architecture', such as the specific positioning of items in grocery stores to change the default choice of foods, have gained considerable attention in recent years. However, there have been relatively few field trials to study their effectiveness for long-term behavioural change. ${ }^{5}$ Nonetheless, a more pragmatic approach would suggest that the current environment, including multiple prompts towards foods and drinks high in saturated fat, sugar and salt, is undermining healthy dietary choices.

This has led to calls for harder policy actions, in particular to control the advertising and promotion of unhealthy foods and drinks. The UK government has developed a 'nutrient profiling' system to identify these items, and now restricts TV and online advertisements for these products that are specifically targeted at children. Consideration is also being given to other restrictions on food marketing and promotions.

\section{Taxation}

Progress has been slow despite years of health promotion and efforts to encourage voluntary action or self-regulation by industry. Continuing increases in the prevalence of obesity in particular have prompted growing calls for greater policy action. Many countries have introduced some form of tax on unhealthy foods or drinks, primarily sugar-sweetened beverages; this includes the UK, which introduced a soft drinks industry levy in April 2018. Economic evaluation of these policies suggests a near-proportional negative impact on sales, and consideration is being given to the extension of such policies to other food categories.

\section{Setting nutrition standards}

Governments have a particular opportunity to intervene in situations where they are responsible for food provision. The UK has nutrition standards for state schools, and hospitals are required to have a food policy covering food provision for patients, staff and visitors. Government Buying Standards set out specific health and sustainability criteria for food procurement, which central government departments and their related organizations are expected to adhere to. There is, however, considerable variation in practice, and scope to extend tighter nutritional standards to other publiclyfunded environments such as care homes and prisons.

\section{Modifying the food environment}

It is clear that there are significant regional variations in the food available in local communities. Recognizing that the food environment sets the context in which food choices are made, communities are increasingly using their devolved powers to address priority issues. For example, evidence of an association between the density of fast-food outlets and the prevalence of obesity has led some local authorities to use planning laws to limit their proliferation, especially close to schools.

\section{Defining the role of health professionals}

Doctors can have both direct and indirect impacts on public health nutrition. Promoting the uptake of nutritional supplements to at-risk groups is a clinical imperative, particularly in primary care. More generally, doctors have the opportunity to promote clear, evidence-based nutrition messages to their patients. Given the large number of consultations, these individual encounters could, if delivered consistently and as part of routine care, build to achieve a population-level impact. Health professionals can also be important advocates for public health nutrition in their governance roles, for example hospital management boards, or as advocates in the general community.

Building public acceptability for intervention will create an environment in which it is more likely that effective policies will be introduced. Doctors have played a vital role in building a strong portfolio of policy action in the UK to reduce the health harms from tobacco. With diet, now a greater public 
health problem than smoking, the time has come to mount similar concerted efforts to support population-level interventions to drive change.

\section{Key References}

1. Newton JN, Briggs AD, Murray CJ, et al. Changes in health in England, with analysis by English regions and areas of deprivation, 1990-2013: a systematic analysis for the Global Burden of Disease Study 2013. Lancet 2015; 386: 2257-74.

2. Public Health England. Government dietary recommendations: government recommendations for energy and nutrients for males and females aged 1-18 years and 19+ years. London: PHE, 2016.

3. Public Health England. National Diet and Nutrition Survey. Results from years 7 and 8 (combined) of the rolling programme (2014/2015 to 2015/2016). London: PHE, 2018.

4. Crockett RA, King SE, Marteau TM, et al. Nutritional labelling for healthier food or nonalcoholic drink purchasing and consumption. Cochrane Database Syst Rev 2018; 2: CD009315.

5. Marteau TM, Hollands GJ, Fletcher PC. Changing human behavior to prevent disease: the importance of targeting automatic processes. Science 2012; 337: 1492-5. 


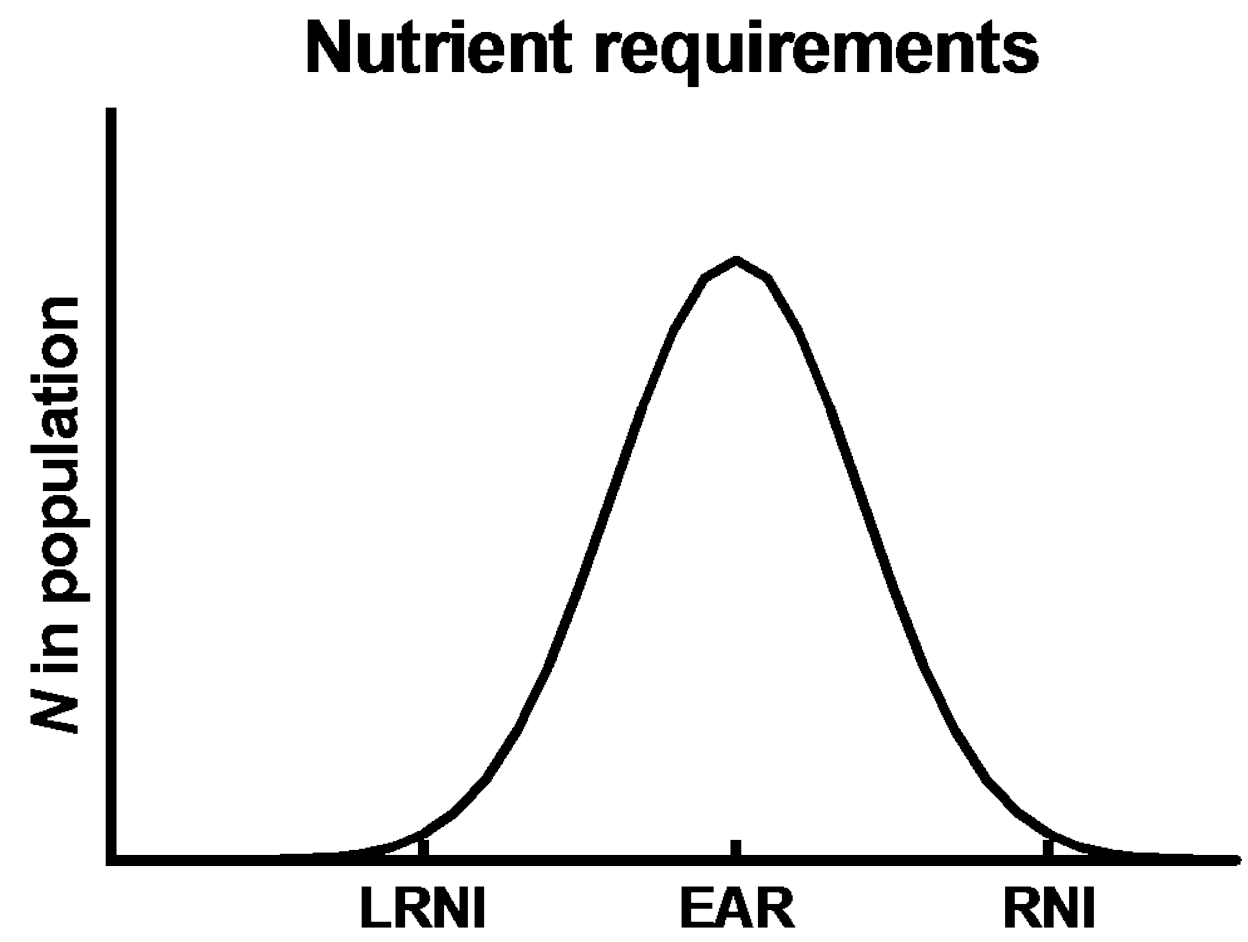

Figure 1 Example DRVs for a specific nutrient 


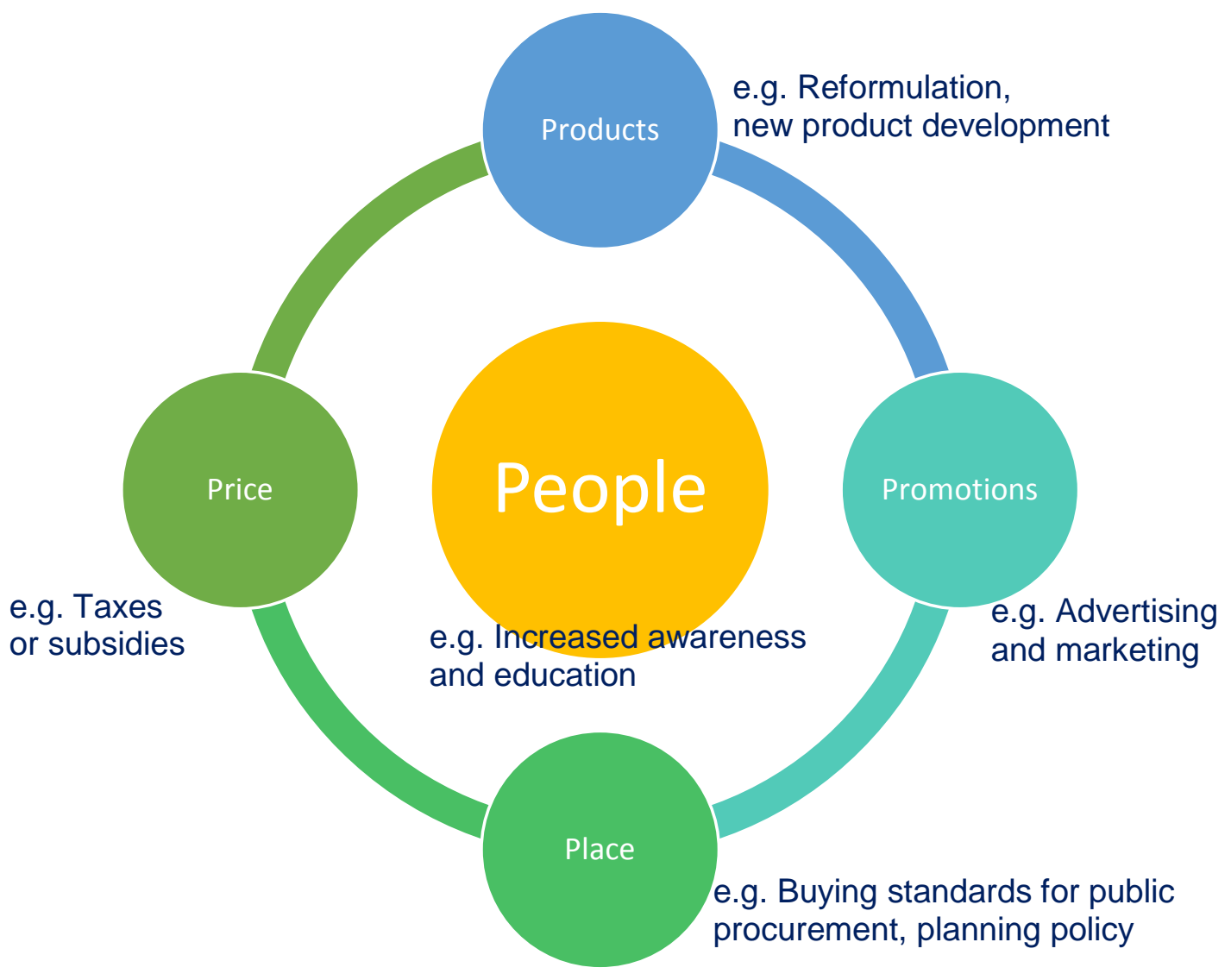

Figure 2 Public health nutrition policy options and examples 
Table 1 Average intake of specific nutrients and food groups of UK adults based on NDNS data (2014/15 to 2015/16) and their comparison to UK dietary recommendations

\begin{tabular}{|c|c|c|c|}
\hline & $\begin{array}{c}\text { Population } \\
\text { average intake }\end{array}$ & $\begin{array}{l}\text { DRV/recommenda } \\
\text { tion }\end{array}$ & Rationale \\
\hline \multicolumn{4}{|l|}{ Specific food groups } \\
\hline 5-A-Day (portions/day) & 4.2 & $\geq 5$ & $\begin{array}{l}\text { Higher intakes associated } \\
\text { with reduced risk of } \\
\text { cardiovascular disease } \\
\text { and stroke }\end{array}$ \\
\hline $\begin{array}{l}\text { Sugar-sweetened } \\
\text { beverages (g/day) }\end{array}$ & 129 & Minimize & $\begin{array}{l}\text { Consumption associated } \\
\text { with higher rates of tooth } \\
\text { decay, type } 2 \text { diabetes } \\
\text { mellitus and weight gain }\end{array}$ \\
\hline Oily fish (g/week) & 56 & 140 & $\begin{array}{l}\text { Higher intakes associated } \\
\text { with reduced risk of } \\
\text { cardiovascular disease }\end{array}$ \\
\hline $\begin{array}{l}\text { Red and processed meat } \\
\text { (g/week) }\end{array}$ & 434 & $\leq 500$ & $\begin{array}{l}\text { Higher intakes associated } \\
\text { with increased risk of } \\
\text { colorectal cancer }\end{array}$ \\
\hline \multicolumn{4}{|c|}{ Energy and specific nutrients } \\
\hline Energy (kcal) & $\begin{array}{l}2100 \text { for men } \\
1640 \text { for women }\end{array}$ & $\begin{array}{c}2500 \text { for men } \\
2000 \text { for women }\end{array}$ & $\begin{array}{l}\text { Excess intake (beyond } \\
\text { energy needs) leads to } \\
\text { weight gain }\end{array}$ \\
\hline Free sugars (\% energy) & $11 \%$ & $\leq 5 \%$ & $\begin{array}{l}\text { Consumption associated } \\
\text { with tooth decay, type } 2 \\
\text { diabetes mellitus and } \\
\text { weight gain }\end{array}$ \\
\hline Fibre (g/day) & 19 & $\geq 30$ & $\begin{array}{l}\text { Higher intakes associated } \\
\text { with reduced risk of } \\
\text { cardiometabolic disease } \\
\text { and colorectal cancer }\end{array}$ \\
\hline Total fat (\% energy) & $33.2 \%$ & $\leq 35 \%$ & \multirow{3}{*}{$\begin{array}{l}\text { Higher intakes associated } \\
\text { with reduced risk of } \\
\text { cardiovascular disease }\end{array}$} \\
\hline Saturated fat (\% energy) & $12.5 \%$ & $\leq 10 \%$ & \\
\hline $\begin{array}{l}\text { Trans fatty acids (\% } \\
\text { energy) }\end{array}$ & $0.5 \%$ & $\leq 2 \%$ & \\
\hline
\end{tabular}


Table 2 Recommendations for supplements of vitamins and minerals for specific subgroups

\begin{tabular}{|l|l|l|}
\hline Supplement & Population subgroup & Advise \\
\hline Folic acid & Women in the first trimester of pregnancy & 400 microgram/day \\
\hline Vitamin D & $\begin{array}{l}\text { Breast-fed infants up to 1 year of age } \\
\text { (Formula-fed infants only when they have }<500 \mathrm{ml} \text { of } \\
\text { formula daily) }\end{array}$ & $\begin{array}{l}8.5-10 \\
\text { microgram/day }\end{array}$ \\
\cline { 2 - 3 } & Children aged 1-4 years old & 10 microgram/day \\
\cline { 2 - 3 } & $\begin{array}{l}\text { Everyone who is not often outdoors, covers their skin or } \\
\text { has dark skin }\end{array}$ & 10 microgram/day \\
\cline { 2 - 3 } & Everyone $>5$ years old during autumn and winter months & $\begin{array}{l}\text { Consider 10 } \\
\text { microgram/day }\end{array}$ \\
\hline Vitamin A & $\begin{array}{l}\text { Infants and children 6 months to 5 years old (who have } \\
<500 \text { ml of infant formula daily) }\end{array}$ & $\begin{array}{l}\text { Consider a } \\
\text { supplement }\end{array}$ \\
\hline Vitamin C & $\begin{array}{l}\text { Infants and children 6 months to 5 years old (who have } \\
<500 \text { ml of infant formula daily) }\end{array}$ & $\begin{array}{l}\text { Consider a } \\
\text { supplement }\end{array}$ \\
\hline Iron & $\begin{array}{l}\text { Women who lose a lot of blood during their monthly } \\
\text { period }\end{array}$ & $\begin{array}{l}\text { Consider a } \\
\text { supplement }\end{array}$ \\
\hline
\end{tabular}




\section{TEST YOURSELF}

To test your knowledge based on the article you have just read, please complete the questions below. The answers can be found at the end of the issue or online here.

Question 1

NEW QUESTION 1

Advisory bodies on healthy eating commonly recommend an amount of many nutrients that meet the dietary requirements of all but $2.5 \%$ of the population.

What term is given to this figure?

A Dietary Reference Value

B Reference Nutrient Intake

C Estimated Average Requirement

D Low Reference Nutrient Intake

E Safe Intake

Correct answer: B

The RNI is the amount of a nutrient that covers $97.5 \%$ of the population needs, while the EAR is the amount that covers $50 \%$ of the population needs, the LRNI the one that covers $2.5 \%$ of the population needs, the $\mathrm{SI}$ is the amount judged to meet the needs of almost everyone, without having undesirable effects, and the DRV is an umbrella term for all the above.

\section{Question 2}

\section{Correct answer:}

\section{NEW QUESTION 2}

In the UK, where is the greatest discrepancy between what is recommended as an ideal diet and actual consumption?
A Excess of free sugars
B Excess of total fat
C Excess of trans fats
D Excess of saturated fat
E Excess of total carbohydrate

Correct answer: A

The current population average intake of free sugars is $11 \%$ of total energy with the recommended intake being $\leq 5 \%$ (discrepancy of $6 \%$ ), while the discrepancy for excess saturated fat is $2.5 \%$; the intake of trans fats is within the recommendations and the intakes for total carbohydrate and total fat are slightly lower than recommended.

\section{Question 3}

Correct answer:

\section{NEW QUESTION 3}

In northern climates, which population group is most at risk of vitamin D deficiency, justifying supplementation? 

A Everyone in winter
B Formula-fed babies
C Individuals with fair skins
D Adolescents
E No one, we produce enough vitamin D from sunlight

\section{Correct answer: A}

Everyone in winter should take a vitamin D supplement, as milk formula is fortified and both adolescents and individuals with fair skin are not a specifically high risk populations for deficiency. 